\title{
La dialéctica afirmativa de lo común
}

\section{A dialética afirmativa do comum}

\begin{abstract}
Carlos Rivera-Lugo ${ }^{(*)}$
Resumen: Este texto plantea el reto que tiene ante sí la Filosofía y Teoría del Derecho de pensar críticamente la potencia histórica anticapitalista de la normatividad societal y comunal que ha emergido a partir del llamado nuevo constitucionalismo latinoamericano en países como, por ejemplo, Venezuela y Bolivia, así como las experiencias de autodeterminación y autonomía comunitaria que han ido proliferando en, por ejemplo, México. Se trata de un nuevo nomos de lo común que se va abriendo paso y trascendiendo el marco estrictamente local, al igual que el jurídico, en sus posibilidades e impulsos transformativos como movimiento real. Se va constituyendo así en un modo alternativo de regulación y estructuración social y política que desborda el horizonte limitado del vigente estado-mercado capitalista. El autor argumenta a favor de una apuesta teórica y práctica que no se limite a la mera negación del orden capitalista presente y sus contradicciones estructurales insalvables. Sobre todo, debe apuntalarse en la afirmación de estas nuevas posibilidades históricas que surgen desde la forma comunitaria o comunal y su fuerza normativa para reordenar nuestro modo de vida colectiva, desde su rica pluralidad constitutiva. De lo que se trata, en última instancia, es de potenciar esa comunidad universal de los pueblos de la que nos habló Karl Marx.

Palabras-clave: Normatividad societal y comunal; Autodeterminación y autonomía comunitária; Regulación y estructuración social.
\end{abstract}

Recebido: 08/2016

Aprovado: $11 / 2016$

Resumo: Este texto coloca o desafio, para a Filosofia e Teoria do Direito, de pensar criticamente o poder histórico anticapitalista de normas sociais e comunitárias que surgiram a partir do chamado novo constitucionalismo latino-americano em países como, por exemplo, Venezuela e Bolívia, bem como as experiências de autodeterminação e autonomia comunitária que se multiplicaram, por exemplo, no México. É um novo nomos que está surgindo e que vai além dos quadros estritamente locais e de suas possibilidades e impulsos de transformação enquanto movimento real. Vai se constituindo, assim, um modo alternativo de regulação das estruturas sociais e políticas que vai além do horizonte limitado da corrente capitalista de Estado-mercado. O autor defende uma aposta teórica e prática que não se limita à mera negação da atual ordem capitalista e suas contradições estruturais insuperáveis. E, para tanto, se apóia na afirmação dessas novas possibilidades históricas que surgem a partir da comunidade, nas formas de regulação que apontam para reordenar nosso modo de vida coletivo e sua rica pluralidade. O que é, em última análise, o que apontava Karl Marx, no sentido de construir uma comunidade universal das pessoas.

Palavras-chave: normas sociais e comunitárias; auto-determinação e autonomia Comunidade; regulação e estrutura social'.

La Filosofía y Teoría del Derecho en Nuestra América necesita pensar críticamente sobre la potencia histórica anticapitalista de experiencias como las de Venezuela y Bolivia, así como las que en México se producen en Chiapas, Guerrero, Oaxaca, Michoacán, Morelos, entre otros. Son las grietas desde las cuales se pueden producir e instituir una nueva ordenación económica, social y política, es decir, un nuevo nomos de lo común, incluyendo un nuevo modo de regulación social y gobernanza que rompa con el Derecho centrado en el estadomercado capitalista.

\footnotetext{
* El autor, de nacionalidad puertorriqueña, es catedrático e investigador independiente en Filosofía del Derecho y del Estado.

Problemata: R. Intern. Fil. v. 8. n. 1 (2017), p. 53-68 e-ISSN 2236-8612

doi:http://dx.doi.org/10.7443/problemata.v8i1.33628
} 
Por nomos de lo común entiendo un proceso social contradictorio, atravesado por relaciones y luchas de poder, bajo el cual se producen las decisiones, los actos o hechos constitutivos que dan sentido a la ordenación política, económica y social de lo común en el mundo contemporáneo. El concepto se inspira, en parte, en ese nomos primordial de la antigüedad griega. Se trata de un nomos focalizado en la comunidad y, más específicamente, en el demos, es decir, el pueblo como fuente material primordial de toda normatividad. En este sentido, el nomos de lo común trasciende la mera legalidad estadocéntrica. El nomos de lo común se manifiesta más allá del puro Derecho y su predominante forma-jurídica. El devenir histórico del ser humano no es producto de reglas y normas jurídicas en abstracto. Es producto de ese hecho histórico constitutivo con una fuerza material y normativa avasalladora: la forma en que una sociedad o comunidad dada se apropia de los medios de producción e intercambio, y cómo determina la distribución del producto y la riqueza social. Se trata de definir el sentido histórico que en cada época anima la producción, apropiación y distribución de riqueza y de poder, lo que constituye la fuente material determinante de las distintas formas de comunidad, sociedad y de todo Derecho o modo de ordenación y regulación. El nomos de lo común se caracteriza por su negación de la propiedad privada liberal-capitalista, y la afirmación de un proyecto histórico bajo el cual la libertad se emancipa finalmente de las cadenas de esa institución y, en su lugar, se potencian formas equivalenciales y comunizantes de propiedad o posesión, así como de distribución.

Ahora bien, hay que romper con la percepción de que las experiencias comunizantes antes mencionadas tratan de procesos o eventos cuya pertinencia es estrictamente local, sin relación alguna entre éstas o más allá de éstas, es decir, a un nivel sistémico o civilizatorio.

Existe un nuevo modo de ordenación política, económica y social que irrumpe, como impulso histórico de lo común, y desborda al Estado actual. Y para mayor interés, tiende a confluir a primera vista con la idea marxista de la comuna como fuente material de una nueva normatividad societal basada en el principio de la autodeterminación más allá de la forma-estado. Son procesos sociales y políticos de naturaleza constitutivos que ofrecen referentes y posibilidades contestatarias nuevas. Claro está, requieren ser problematizados -y no idealizados- desde la filosofía y teoría crítica de lo jurídico en particular y lo normativo en general. En fin, hay que pensar fuera del marco de la experiencia sociojurídica prevaleciente. En ausencia de ello, seguiremos prisioneros de la positividad jurídica burguesa y sus horizontes interpretativos y prácticos limitados, por no decir francamente yermos.

Hay que repensar el tema de lo común desde la experiencia material de 
toda la sociedad contemporánea, especialmente la latinoamericana. Hay que superar el reduccionismo del tema de lo común a lo indígena o a lo local; así como su sumisión a la forma-jurídica estadocéntrica. Ello tiende entonces a particularizar demasiado su pertinencia histórica como forma alternativa de ordenación social y normativa al existente bajo el nomos del capital. No se trata de reducirlo a un marco étnico y menos a verlo como un mero "retorno a la naturaleza". Tampoco tiene que ver con su exclusiva focalización en torno a lo local o lo particular. Sería condenarlo a no erigirse en alternativa al capitalismo.

El reto que hoy se confronta ante la multiplicidad de grietas que se abren y focos que se activan, es como transitar nuevamente desde un espacio estratégicamente limitado a uno estratégicamente más comprehensivo. No se trata de negar el carácter acentrado y segmentado de una historicidad humana que ha probado ser más aleatoria de lo deseado. ${ }^{2}$

No se trata de retornar a una concepción metafísica del poder, con sus determinismos absolutos. Se trata de entender a la altura de nuestros días la dialéctica que media entre los procesos microsociales y los procesos macrosociales. De ahí que en el fondo se trata de abordar la cuestión desde la siguiente perspectiva: cómo haremos para producir una nueva subjetividad, una nueva ética de la organización social y política desde la cual potenciar una nueva situación de fuerza que nos permita sustraer la producción y el intercambio social, así como también la gobernanza y los procesos de decisión política y de prescripción normativa, fuera del marco y la lógica de la economía-mundo capitalista. Es en este contexto que hay que situar lo común. Es en ese contexto que se tiene que producir el diálogo vivo entre las diferentes narrativas y fuentes de lo común, sea la comuna marxista, la comuna bolivariana, la comunalidad oaxaqueña o el caracol zapatista.

Cuando me refiero a lo común lo hago esencialmente como forma primordial ordenadora de un modo de producción e intercambio, así como nuevo orden civilizatorio que supere la forma valor y patrimonialista característica del capitalismo. No hay que olvidar que la propiedad privada fue la formación secundaria de la sociedad, mientras que la formación basada en la propiedad común constituye la formación primaria. ${ }^{3}$ La propiedad privada es la ausencia de lo común y el comunismo tiene como su eje la construcción de lo común.

Estamos hablando de una forma societal equivalencial que existe como impulso primordial pero que ha sido sofocada en toda su potentia por los amarres que le han impuesto las sociedades no-equivalenciales de clases, particularmente el capitalismo. ${ }^{4}$ En ese sentido, ese deber ser latente que anida en la sociedad actual necesita ser liberado.

Lo común ha sido un concepto o categoría insuficientemente desarrollada, ya que hasta ahora las sociedades de clase, en sus fines no equivalenciales, han 
preferido subordinar sus expresiones a la forma privada o estatal. Se trata de un fenómeno que se potencia desde la inmanencia y en esa medida constituye una grieta que potenciada puede conducir a la ruptura. Lo común son bienes y construcciones comunes. Son nuestras luchas, pero también nuestras creaciones sociales colectivas; es nuestro lenguaje y los espacios de acción comunicativa y asociativa que compartimos; son nuestros saberes y nuestras riquezas naturales; es la autodeterminación local, regional, nacional e internacional como gobernanza de todos, por todos y para todos. Lo común es nuestro modo históricamente determinado de estar juntos y cooperar los unos con los otros en torno a fines compartidos y colectivamente beneficiosos. Lo común se realiza en la cabal socialización de su gestión y producto. Lo común se encarna en todos y todas; lo común es de todos y todas. El res communis marxista, pues, no se reduce al mero hecho de la existencia de bienes comunes. Posee implicaciones ontológicas: es una potenciación del ser y su libertad, más allá de la muchas veces tiránica necesidad que pretende limitar las posibilidades de nuestro hacer en las circunstancias presentes.

Hay que reconocer lo común como otro modo de ordenación de la vida, radicalmente alternativo, frente a ese declive de la relación público-privado o el estado-mercado. Y del mismo modo en que lo privado es criatura del capitalismo y lo público del socialismo o el social-reformismo, lo común se inscribe en elcomunismo, es decir, como movimiento real de comunización que niega y supera el orden de cosas actual. Lo que significa que a partir de las tendencias empíricamente constatables, incluyendo las contradicciones inherentes de los ciclos sistémicos de acumulación que han caracterizado al capitalismo desde su incepción, no hay otra posibilidad real de potenciar un nuevo modo de producción, intercambio y regulación social, fundamentado en una real libertad e igualdad, que no sea como parte de ese movimiento real de lo común.

En ese sentido, se trata no sólo de una negación de lo existente sino que, sobre todo, de la potenciación de una nueva esfera de organización económicopolítica ante la incapacitación creciente de las esferas tradicionales, privada y pública, para atender efectivamente el bien común, sobre todo ante el maridaje actual de ambas bajo el modelo neoliberal de acumulación por sobre-explotación y desposesión prevaleciente en el mundo capitalista. La forma-común, formacomunidad o forma-comuna se presentan en la alternativa a la forma-valor o forma estado-mercado prevaleciente. Es lo que he calificado en otra parte como comunismo jurídico o, si se prefiere, comunismo normativo, es decir, el movimiento real que sirve de fuente material de una nueva normatividad societal o modo de ordenación social que niega y supera la estructuración históricamente concreta del Estado de Derecho liberal-capitalista y su desprestigiada racionalidad abstracta y formal. ${ }^{5}$ 
Un ejemplo concreto en Nuestra América de ese comunismo jurídico y normativo que históricamente representa un impulso de lo nuevo, a modo de potentia que deviene como posibilidad real dentro de las circunstancias actuales, es la experiencia material representada por la comuna venezolana. Se trata de una experiencia que se inspira no sólo en el propio contexto históricosocial de Venezuela sino que también en las irradiaciones de la Comuna de París de 1871. Representa una socialización tanto normativa como político-económica de los procesos decisionales al interior de la sociedad venezolana. Se trata de potenciar una transición hacia lo común como nueva forma y fuente hegemónica de producción normativa y decisión político-económica.

La comuna es uno de los rostros de lo común entendida como ese impulso societal equivalencial siempre latente como potentia permanente. Bruno Bosteels nos propone la siguiente hipótesis:

\begin{abstract}
Y es que la comuna me parece ser el nombre de un anhelo universal de emancipación de la humanidad que, si bien tiene sus raíces en aquella comuna o comunidad originaria que fue tan violentamente desgarrada y destruida durante el continuo proceso de acumulación primitiva del capital, también la trasciende y la excede por todos lados. Si no fuera así, la referencia a la comunidad, incluso al interior de un proceso plurinacional que quiere fortalecer una especie de socialismo comunitario para el siglo veintiuno, corre el riesgo de encerrarse en la particularidad de esta o aquella comunidad como algo dado y no como algo que se produce, así como no se recupera o se encuentra sino que se debe producir la asociación libre de la que se habla en el socialismo marxista pero también utópico del siglo diecinueve.
\end{abstract}

Y concluye:

La comuna, o lo común, podría ser el nombre de aquello que, si bien hace eco de las voces que claman por recordar la violencia que sufrieron las comunidades, hace también alusión a la producción de un nuevo común, por así decirlo, postcapitalista. ${ }^{6}$

En ese sentido, no se reduce o se remite inexorablemente a la fuente previa, una especie de sustancia natural, ni tan siquiera a una especie de comunismo ideal. La comuna ha retornado en la época contemporánea, precisamente ante el imperativo de repensar el horizonte de la época actual y la persistencia histórica de la propuesta comunista o de lo común, y su pluralidad de fuentes ideales y materiales que han vuelto a hacer acto de presencia, sobre todo en el contexto latinoamericano, desde el marxismo hasta las cosmovisiones indígenas.

En su obra cumbre El principio esperanza, señala el filósofo marxista alemán Ernst Bloch lo siguiente:

En sentido primario, el hombre que aspira a algo vive hacia el futuro; el pasado sólo

Problemata: R. Intern. Fil. v. 8. n. 1 (2017), p. 53-68

e-ISSN 2236-8612 
viene después; y el auténtico presente casi todavía no existe en absoluto. El futuro contiene lo temido o lo esperado; según la intención humana, es decir, sin frustración, sólo contiene lo que es esperanza. ${ }^{7}$

En todo presente, además de lo que se pueda observar a primera vista, existe un impulso, una ruptura, una incubación y una anticipación de lo que aún no ha llegado a ser. La esencia de la humanidad no está, en ese sentido, en lo que ha sido sino en aquello que sueña ser. Vivimos en una era en que la esperanza se va encarnando como libertad común, como resultado de una construcción social plural.

Es así como el comunismo, es decir, la experiencia material de lo común surge como una construcción permanentemente presente y a la vez forjadora de futuro. No se trata de una utopía permanentemente postergada, sino que se materializa en esa constelación de prácticas sociales y políticas que van transformando las conciencias y las realidades en todos los ámbitos. El comunismo es el acto constituyente de lo esperado que irrumpe en la historia nuestra de cada día.

Al respecto señala Álvaro García Linera: "El horizonte general de la época es comunista. Y ese comunismo se tendrá que construir a partir de capacidades auto-organizativas de la sociedad, de procesos de generación y distribución de riqueza comunitaria, de autogestión". No obstante, seguidamente advierte que si bien ese es el horizonte general, el horizonte inmediato es algo más concreto: "la conquista de la igualdad, redistribución de riqueza, ampliación de derechos. La igualdad es fundamental porque quiebra una cadena de cinco siglos de desigualdad estructural, ese es el objetivo de la época".

La potenciación radical de la democracia y la descolonización plena de la vida se convierte así en un paso imprescindible para abrirle paso a formas más avanzadas de lo común. Y es que el comunismo no es una ideología, ni una nueva realidad que se impone desde arriba por una autoproclamada vanguardia y menos por un Estado, sino es el movimiento real de la sociedad mediante el cual se supera el estado de cosas actual a través del despliegue decidido de la autodeterminación y la construcción plural de lo común. Es la constitución de un nuevo tiempo y espacio histórico como capacidad común de producir y reproducir nuestro modo de vida en plena libertad, la única real alternativa posneoliberal y poscapitalista o, si se prefiere, transcapitalista.

Con respecto a esto, es vital acabar de entender que la comuna es el modelo de Marx. Sobre todo, a partir de la Comuna de París se introduce un desarrollo teórico importante en éste que le llevó a aquilatar las particularidades que, a pesar de sus contradicciones, asumen algunas experiencias históricas de tipo comunitarias como, por ejemplo, en el caso de Rusia, Castilla y América del Sur. Al respecto señala García Linera: 


\begin{abstract}
"Consciente de esto, Marx no se puso a glorificar la comunidad en su estado actual, ni mucho menos se puso a inventar medidas caritativas para pedir al estado burgués que 'resguarde' la comunidad. Vio, en cambio, que la comunidad ancestral sólo podía desarrollarse y hacer prevalecer sus rasgos colectivistas en tanto fuera capaz de promover levantamientos generales en contra del régimen capitalista, esto es, en tanto las masas comunitarias llevaran a cabo una guerra revolucionaria como parte fundante de la Revolución Socialista de trabajadores de la ciudad y el campo que pusiera fin tanto a las fuerzas individualistas al interior de la comunidad, como al régimen capitalista que la acosa por todas partes. Entonces, la comunidad no sólo habrá de conservarse, sino que habrá de recuperar sus condiciones primarias de asociación y control de los productores sobre la producción; y lo mejor de todo, lo hará en condiciones nuevas y superiores por la existencia de nuevas fuerzas y riquezas productivas y por la presencia mundial del proletariado, que posibilita la incorporación de esas riquezas y su control social, común, comunitario por los trabajadores directos; por tanto, superación de las antiguas condiciones que por siglos empujaron a la comunidad hacia su lenta disolución".
\end{abstract}

Y concluye García Linera: "Estas condiciones revolucionarias previstas por Marx hace ya cien años, son las que en la actualidad empiezan a despuntar con gigantesca fuerza con gigantesca fuerza en la lucha y en los preparativos revolucionarios de comunarios y proletarios" a través de la América nuestra. ${ }^{9}$

Como advierte Bosteels, se halla a partir de ese momento en la obra teórica de Marx "un acercamiento histórico y político más amplio a esas otras comunas que son anteriores a la Comuna de París y que quizá en términos de potencial emancipatorio, la trascienden hacia un futuro todavía impredecible". ${ }^{10}$

Luego de la experiencia de la experiencia de la Comuna de París, tanto Marx y Engels comienzan a vislumbrar como imperativo político el desarrollo de una forma de ordenación política y normativa que se niegue a moverse al interior de la forma estatal. En la medida en que Estado y sociedad, sociedad política y sociedad civil se confundan, el Estado como hasta ahora lo hemos conocido se diluye hasta desaparecer.

En su obra Del socialismo utópico al socialismo científico, Federico Engels nos dice: "Cuando el Estado finalmente se convierta en representante efectivo de toda la sociedad será por si mismo superfluo". Asimismo, en su carta a August Babel, de 1875, Engels señala que la superación histórica del Estado es en dirección al desarrollo, en la alternativa, de la comunidad. Se trata de la comunidad como nueva forma de gobernanza. He ahí el paradigma comunista empuñado por Marx y Engels.

Para Marx, la concepción idealista del Estado, según postulado a partir del liberalismo burgués, se abstrae de la realidad. El gobierno del Estado moderno no es más que una junta que administra los negocios comunes de toda la clase burguesa. A este Estado hay que transformarlo o, mejor dicho, superarlo. Hay que dejar atrás toda ilusión de que puedan ser utilizados para, 
desde éste, construir la nueva sociedad: la res communis. Al respecto nos puntualiza García Linera:

El transformar las relaciones de orden vital, lo tiene que hacer todo revolucionario. Pero sin dejar de lado el transformar las relaciones de poder del estado. Hay que pelear por el poder del estado, no para tomarlo, sino para transformar desde abajo una nueva estructura de poder, un nuevo estado. Y como herramienta para continuar el proceso de revolucionarización del resto de las actividades humanas. ${ }^{11}$

En ese sentido, Marx propuso la constitución material de un Estado cuyo fundamento es la soberanía popular, a partir de la cual se irá socializando hasta extinguirse. Bajo éste, el pueblo como soberano popular es el Estado real, un Estado que deviene permanente en su contrario: un no-Estado encarnado en el soberano popular. Se trata de un "Estado" que, privilegiando la soberanía popular, se deja reabsorber por la sociedad, para extinguirse progresivamente conforme la sociedad misma. La reabsorción propuesta por Marx incluye la reapropiación societal de todo proceso social, no sólo político sino que también económico y normativo. Se reconoce así el carácter directamente político de la sociedad civil, superándose así la dicotomía hegeliana entre sociedad política y civil. Se trata del desarrollo de una democracia real que constituya una revolución permanente que conduzca al autogobierno popular. En ese sentido, la emancipación se produce mediante la superación de los intereses particulares hacia los intereses comunes. El ser humano y el ciudadano se hacen uno.

Para ello hay que acabar con el Estado de Derecho abstracto y formal. La ordenación normativa debe fundarse en la sociedad y no en una ley formal que sólo oculta, al fin y a la postre, la voluntad y el interés de la clase burguesa. Marx rompe así incluso con el idealismo jurídico hegeliano. Desechados todos los a priori ideales, de lo que se trata es de dar rienda suelta a los elementos rupturistas contenidos en la nueva sociedad. ${ }^{12}$

¿Estado o comunidad?, se pregunta Dussel. ${ }^{13}$ Desde esta perspectiva, me parece una falsa disyuntiva.

Según Alain Badiou, la apuesta comunista no trata en última instancia de tomar el Estado, sino de romper con él. La Comuna de París constituye la combinación de lo social y el poder. La Comuna, como acontecimiento histórico, tuvo el efecto de dejar planteado no sólo la necesidad sino que la posibilidad de romper con la subordinación política y social de los trabajadores y del pueblo en general. Se destruyó para siempre el orden basado en la alegada incapacitación subjetiva de éstos para gobernarse a sí mismo. La Comuna creó la posibilidad de una política autónoma de los trabajadores. Dejó establecido lo que serían los nuevos fundamentos del mundo. Urge, según el filósofo francés, que la posibilidad de transformación revolucionaria de la situación actual se reconstituya en torno a esta ruptura. ${ }^{14}$ 
Las sociedades latinoamericanas todas están experimentando esta potenciación exponencial de hechos y experiencias de lo común en múltiples ámbitos de la vida social, sobre todo como contestación a la subsunción neoliberal de la vida toda a las lógicas de acumulación triturantes del capital en estos tiempos. Dichas contestaciones poseen una singular fuerza normativa de la que a ratos no estamos conscientes pues estamos demasiado enfocados como juristas a sólo aquilatar los efectos constitutivos y universalizadores de los actos y las decisiones gubernamentales. Se trata de identificar, por lo tanto, la potencia transformativa de lo común como referente pertinente dentro de la búsqueda actual de propuestas concretas de recambio más allá de las ancladas en el sistema capitalista y el derecho burgués. Y es que no podemos dejar de reconocer que el impulso contestatario de lo común confronta la reacción contrarrevolucionaria de las élites económicas, sociales y políticas capitalistas hoy hegemónicas en la mayor parte de nuestros países, las cuales buscan continuamente controlar y aplastar toda posibilidad de cambio o de ruptura.

$Y$ es que si atravesamos por una crisis sistémica en la actualidad, éste no sólo trata de la crisis del capitalismo sino que también implica la incapacidad para potenciar una transformación revolucionaria del sistema que imponga su voluntad de poder sobre los designios actuales de los dueños y adláteres del capital. Alain Badiou se refiere a ello como la crisis de la idea de "revolución", es decir, la crisis de la idea de que es posible la organización de un mundo muy otro más allá del capitalismo. En ausencia de ello, nuestras expectativas de cambio se constriñen a meramente reformar lo existente sin cambiarlo en esencia.

La mera negación del orden establecido no es suficiente. Lo que consolida y proyecta estratégicamente a un movimiento no es sólo la capacidad de protesta o de resistencia sino que, sobre todo, la capacidad para articular una declaración propositiva y reordenadora con implicaciones prácticas. Es en este contexto que resulta imperativo la recuperación de la proposición afirmativa de lo común o, si se prefiere, del comunismo como expresión material de la posibilidad real de emancipar la libertad de la camisa de fuerza que ha representado la institución de la propiedad privada liberal-burguesa y las formas autoritarias de gobernanza que le acompañan. ${ }^{15}$

Marx insiste en que no es cuestión de rebasar las deficiencias de las actuales relaciones de propiedad hacia formas más racionales e incluyentes. En el corazón de la institución de la propiedad privada burguesa yacen leyes económicas que sólo conocen de la fría necesidad del capital. De ahí la inescapable necesidad de su transformación progresiva hacia su abolición. Por ello afirma que "la propiedad privada no es una relación simple y mucho menos un concepto abstracto, un principio, sino que consiste en la totalidad de las 
relaciones burguesas de producción". ${ }^{16}$ Se confronta como tal o se pagan las consecuencias fatales de su minusvaloración. Y es que estoy convencido de que nuestro orden civilizatorio, bajo el capitalismo, ha llegado a una fase determinada de su desarrollo, en que, como dijo Marx en el "Prólogo" a la Contribución a la crítica de la economía política, las fuerzas productivas de la sociedad han entrado "en contradicción con las relaciones de producción existentes, o, lo cual no es más que su expresión jurídica, con las relaciones de propiedad en cuyo interior se habían movido hasta entonces". Habiendo contribuido en su momento al desarrollo exponencial de las fuerzas productivas, estas relaciones y la distribución cada vez más desigual de la riqueza que se da bajo éstas, se han convertido hoy en trabas de para la potenciación continuada de esas fuerzas dentro de un proceso de producción de naturaleza cada vez más social y cuyas innovaciones mayores privilegian más la cooperación incluyente sobre la competencia excluyente. ${ }^{17}$

Ya lo decía Marx: una sociedad es plenamente libre en la medida en que predomina la asociación libre e igualitaria de sus miembros tanto en el plano de la producción como de la gobernanza. En fin, resulta imperativo la constitución de una nueva subjetividad político-económica y normativa, para potenciar esa nueva posibilidad que está latente en las actuales circunstancias. Hay que reinventar nuestra comprensión de lo común a partir de nuevas formas de producción, gobernanza y regulación societal, para evitar seguir errando o procrastinando.

Volviendo al caso de Venezuela, su propuesta de Estado comunal no trata de algo totalmente configurado o ya realizado. Está en gestación, no sin sus tribulaciones y resistencias. Se trata de un poder popular que, a partir de la institución de las misiones ${ }^{18}$ y ahora bajo las comunas, nace desde abajo y se amplía a todos los ámbitos de la vida del país como parte de una reestructuración de la llamada geometría del poder existente. Ello se ha percibido como una amenaza para las competencias tradicionales de los municipios, la burocracia del Estado central y las distintas instrumentalidades gubernamentales. Se va gestando en lo inmediato un poder dual que debe ser sucedido por un poder total, anclado en las instancias locales e inmediatas de lo que será el ejercicio de la soberanía popular dentro de una democracia real y absoluta como nuevo horizonte de la gobernanza.

En una de sus últimas intervenciones ante sus colaboradores más cercanos en el gobierno, Hugo Chávez Frías hizo hincapié en que el criterio para medir la efectividad de la socialización hacia lo común no es el jurídico, es decir, lo que declara la Constitución o las leyes, sino en qué medida las políticas adoptadas se traducen activamente en la institución y consolidación sólida de un modo realmente democrático de autogestión social. Se necesita desarrollar "una 
red que vaya como una gigantesca telaraña cubriendo el territorio de lo nuevo, sino fuera así, esto estaría condenado al fracaso; esto sería absorbido por el sistema viejo, se lo traga, es una gigantesca amiba, es un monstruo el capitalismo". De ahí que afirmara: "icomuna o nada!". Y puntualizó: "Cuidado, si no nos damos cuenta de esto, estamos liquidados y no sólo estamos liquidados, seríamos nosotros los liquidadores de este proyecto. Nos cabe una gran responsabilidad ante la historia". ${ }^{19}$

En la ley orgánica de las comunas de 2009, éstas fueron concebidas como un paso en dirección a ese Estado Comunal. Se trata del proyecto favorito de Chávez de destruir el Estado burgués que tanto está obstruyendo el avance de la revolución bolivariana. De ahí su insistencia en "icomuna o nada!". Para mayo de 2015 existen sobre 1,100 comunas registradas en el país, y otras tantas en construcción. No hay un estado en Venezuela donde no exista una. Han empezado así a desplegar su potencialidad latente. Surgen por propia iniciativa de las mismas comunidades, que son quienes deciden hasta dónde extender los límites geográficos, en función de su propia historia y sus realidades cotidianas. Éstas redactan una especie de Constitución comunal conocida como Carta Fundacional. Dicha Carta debe ser refrendada por la comunidad. Una vez instituida, la comuna cuenta en su estructura con una serie de órganos, entre los cuales se destacan el Parlamento Comunal, la Contraloría Social, el Ejecutivo, y el Banco Comunal.

Se plantea así estratégicamente una socialización de la producción social desde la comuna. Se parte de la premisa de que la economía comunal tiene que sostenerse a partir de los principios de la autogestión y la autosustentabilidad, de conformidad con el bien colectivo. La economía política venezolana debe tener como eje y fuente de sus decisiones, la soberanía del pueblo organizado comunalmente, soberanía cuyo fin no se agota en el espacio local sino que trasciende para abarcar al pueblo venezolano todo. Sólo es soberano quien efectivamente decide, tanto en el plano político como en el económico, aún en el caso de la llamada propiedad social. Sólo así se puede ir arrinconando el control que ejerce la institución burguesa de la propiedad privada o el control estatista sobre los medios de producción. Sólo de esa manera se puede avanzar en torno a la estructuración, desde lo común, de las relaciones sociales de producción y la organización del trabajo. He aquí el nudo gordiano que debe romperse si de verdad se ha de avanzar hacia "un socialismo bolivariano del Siglo XXl" apuntalado en el poder comunal y no en el poder burocrático del Estado.

México también ha sido testigo de distintas vertientes del fenómeno comunero, aunque con raíces e influencias diversas. ${ }^{20}$ Según Adolfo Gilly, en Morelos aparece una reedición local de la Comuna parisina entre 1914-15, que 
sirve de antecedente incluso a la insurgencia del Ejército Zapatista de Liberación Nacional a partir de 1994 en Chiapas y la fuerza constitutiva que ha demostrado con la construcción de los "caracoles". También está la Comuna de Oaxaca (2006) y la más reciente Comuna de Cherán (2011 hasta el presente) $)^{21}$.

La Comuna de Oaxaca $^{22}$ constituye expresión de eso que Jaime Martínez Luna, entre otros, han bautizado como comunalidad, fenómeno mayormente anclado en la historia y la cosmovisión indígena. Vale puntualizar que en el estado de Oaxaca, dos terceras partes de los municipios están organizados bajo la forma comunal; el 90 por ciento de la propiedad sobre la tierra es comunal y no privada.

Según Martínez Luna, para entender la comunalidad, hay que entender que ésta no brota de los criterios cuantitativos del mercado capitalista sino que de criterios cualitativos como "la reciprocidad, la complementariedad, el afecto":

\begin{abstract}
Volvamos al sentido común, esta es una tarea obligada para descolonizarnos, es un deber para entender lo nuestro. Somos autónomos en tanto nos medimos a nosotros mismos con nuestros parámetros, con nuestros valores. Somos autónomos en la medida que nuestras asambleas representan y consensan nuestras decisiones. Somos nosotros en la medida que no partimos de lo que otros quieren que seamos, somos nosotros en la medida que no hay quien nos diga cómo vestirnos, hablar en público, caminar, jugar y hacer nuestra vida cotidiana. ${ }^{23}$
\end{abstract}

Martínez Luna insiste en que el ser humano está definido por su contexto inmediato y a partir de éste es que se desarrolla su pensamiento. Erving Goffman $^{24}$ diría que se trata de privilegiar los marcos de experiencia propios de la comunidad. ParaMartínez Luna, se trata de un marco natural como espacio generador de actitudes, usos, costumbres y normas respetuosas de la diversidad de los miembros de la comuna. Según éste, la naturaleza genera formas de convivencia concretas, entre éstas la asamblea. Ello incluye un principio de representación que no niega al otro sino que se realiza por medio de éste, por medio de la comunidad. Esta realidad asociativa, basada en el trabajo y cooperación colectiva, es la comunalidad.

¿Dónde está la justicia? Para la comunalidad, ésta sólo puede resultar de la autodeterminación jurídica y normativa:

"La justicia no es un simple acuerdo legal, que siempre es materia de negociación entre discurso y forma, es más bien la respuesta popular de lo que debe hacerse y como tal la ley legítima, la que todos aceptan y la que todos respetan. No siempre es recomendable seguir la legalidad que la sociedad nacional nos ha impuesto porque tiene una fuerte carga de autoritarismo, negociación, componenda y corrupción. Es necesario entender que la justicia la pueden decidir los hombres, y no solamente los letrados porque éstos de ella viven, sino también aquellos seres que desde su práctica social empiezan a construir aciertos de gran envergadura.

El derecho tradicional lo hemos ejercido siempre. Sin embargo pensamos que no es posible seguir dependiendo de reglamentos y leyes que no retoman nuestra

Problemata: R. Intern. Fil. v. 8. n. 1 (2017), p. 53-68

e-ISSN 2236-8612 
experiencia." $^{25}$

La solución que Martínez Luna propone es el apuntalamiento y desarrollo de la comunalidad en toda Oaxaca y, de ser posible, en todo México y el mundo. No le interesan las soluciones parciales sino totales. Para ello, insiste en el imperativo de entender y reafirmar la comunalidad pues en ella puede estar la posibilidad real de otro futuro basado en la autodeterminación política y la autosuficiencia económica de las comunidades. Para ello, puntualiza, habrá que ir más allá del Estado y del "estado de derecho" actual cuyos valores fundamentales son la propiedad y apropiación privada, el individualismo y la competencia adversativa. Hay que dejar atrás la institución de la propiedad privada, la cual reduce toda valorización de las cosas y de las vidas a meras mercancías. La tierra y sus frutos deben ser de todos. La autodeterminación debe ser el principio rector de la gobernanza. En ese sentido, la comunalidad debe representar una alternativa real de organización social a la liberalcapitalista.

En fin, en la proposición afirmativa de la comuna hallamos potencialmente un terreno común sobre el cual articular ese otro mundo posible más allá del capitalismo. Su pluralidad de experiencias y fuentes constitutivas, desde la proletaria hasta la indigenista, desde la marxista hasta la anarquista, desde lo local hasta lo nacional e internacional, presentan un espacio bastante amplio de convergencia. La comuna ha demostrado constituir una forma de gobernanza incluyente y expansiva, apuntalada por los condenados de la tierra, ese proletariado ampliado de la ciudad y del campo que se sienten compelidos a enfrascarse en la lucha por la emancipación definitiva de su trabajo y sus frutos de todo régimen de explotación del hombre por el hombre, es decir, de todo régimen cuyo eje sea la institución de la propiedad privada burguesa.

En ese sentido, discrepo de la apreciación reduccionista de Félix Patzi Paco cuando señala:

“Lo comunal no se basa en la idea del 'común' (commons), ni en la de la 'comuna'...Lo
comunal es otra cosa. Deriva de formas de organización social que existían antes de
los incas y los aztecas, así como de las experiencias incaicas y aztecas durante sus
500 años de supervivencia, primero bajo el mundo colonial español y luego bajo los
Estados-nación independientes. Para que se haga justicia a lo comunal, tiene que
entenderse no como proyecto izquierdista (en el sentido europeo) sino como un
proyecto decolonial". ${ }^{26}$

Sin embargo, es ésta otra falsa disyuntiva, a pesar de las tensiones que ha habido a partir de abordajes ortodoxos, mecanicistas o sectarios, especialmente provenientes de algunos izquierdistas portadores de lo que Bolívar Echeverría llama un "comunismo abstracto". ${ }^{27}$ La emancipación del 
trabajo de las lógicas triturantes de la propiedad privada capitalista no se puede solucionar exclusivamente en un plano local y cultural, desde una perspectiva decolonial divorciada de la dimensión social que por necesidad la enmarca, en términos globales y estratégicos, dentro de una lucha de clases que supera, en última instancia, toda posibilidad de reducirla a un plano estrictamente local o familiar. Se trata de reflexionar críticamente sobre las diversas experiencias materiales de las personas para asumir lo común en estos contextos, aún más allá de las formas individuales y familiares de gestión común, hacia desarrollos históricos nuevos de la forma-comunidad que lleve también a asumir la producción como un proceso social común y la ruptura con las influencias corruptoras del Estado-nación burgués. Hay que atreverse a imaginar, como invita Luis Villoro, "un nuevo modelo de comunidad" en que "la comunidad sería la construcción de un mundo otro, por la voluntad concertada de todos". ${ }^{28} \mathrm{Se}$ trata de la posibilidad de una comunidad universal basada en la reciprocidad solidaria anclada en un bien común.

Por ejemplo, la experiencia comunera de los zapatistas en Chiapas con la constitución de los "caracoles" apela a la repotenciación de una condición comunitaria que anida históricamente como impulso originario vital de la vida en común. Se trata de espacios de autogobernanza, sin depender del Estado ni de su reconocimiento, caracterizados por una democracia participativa. Tanto el ámbito territorial de validez, así como la eficacia o legitimidad de las decisiones y las normas aprobadas, están determinadas por las estructuras autónomas adoptadas, incluyendo un sistema normativo propio, y la voluntad de poder constitutivo representado por los integrantes de las propias comunidades. Ahora bien, como puntualiza Pablo González Casanova, el "caracol" si bien arranca de lo local y lo particular, se plantea también la presencia de lo nacional y lo universal en la medida en que se plantea un horizonte anticapitalista. ${ }^{29}$

Como advirtió en su momento Mariátegui, la singularidad del indígena no sólo está determinado por su identidad cultural sino que también por su condición de clase. Cada sujeto adquiere su sentido no sólo a partir de su espacio inmediato sino que como parte de una totalidad que trasciende ineludiblemente lo particular. Se trata en ese sentido de construir "un mundo donde quepan todos los mundos", como declaran los zapatistas. El sentido de lo común no puede por ello replegarse a lo local y lo particular, sino que tiene que alzarse más allá, no por capricho ideológico de nadie sino por necesidad material de la vida misma y del marco estratégico en que se desarrolla. Y si alguna duda cabía de ello, ésta se ha disipado bajo el actual modelo neoliberal de acumulación por desposesión que pretende subsumir totalmente a los pueblos y comunidades indígenas, con sus tierras, bajo sus lógicas ampliadas de explotación y mercantilización. El capital no da tregua desde su proceso actual de proletarización ampliada de la 
sociedad toda. Ello a su vez ha potenciado un progresivo hermanamiento entre las diversas vertientes de contestatación que se han escenificado, desde las resistencias inmediatas de lo local hasta las refundaciones revolucionarias de los espacios nacionales o plurinacionales.

Y es que la verdadera historia de la comuna ha sido la de la dialéctica contestataria del pueblo trabajador, desde su rica pluralidad constitutiva, por articular e implantar nuevas condiciones de existencia. De lo que se trata, en última instancia, es de potenciar esa comunidad universal de los pueblos de la que nos habló Marx.

\footnotetext{
${ }^{1}$ A tradução do resumo e palavras-chave para o português foi feita por um dos organizadores deste número especial, Professor Dr. Enoque Feitosa, a pedido do autor.

2 ¿Existe tal cosa como un origen primordial o un orden subterráneo que explica tanto el principio así como el fin de toda realidad histórica? ¿Un gran acontecimiento aleatorio que rompe con el vacío, con la nada? De ahí en adelante, ¿qué función cumple el pensamiento? Subirse al tren en marcha, eternamente en marcha, nos dice Louis Althusser. La positividad prevalece siempre sobre la negatividad. Véase al respecto su interesante y provocadora obra Para un materialismo aleatorio, Arena Libros, Madrid, 2002, pp. 31-71.

3 Álvaro García Linera, Forma valor y forma comunidad, CLACSO-Muela del Diablo-Comuna, La Paz, 2009, p. 251.

${ }^{4}$ Enrique Dussel, 16 tesis de economía política: Interpretación filosófica, Siglo XXI Editores, México, D.F., 2014, p. 183.

${ }^{5}$ Carlos Rivera Lugo y Oscar Correas Vázquez, El comunismo jurídico, UNAM-CEIICH, México, DF, 2013, p. 24. Véase también a Carlos Rivera Lugo, ¡Ni una vida más para el Derecho! Reflexiones sobre la crisis actual de la forma-jurídica, Centro de Estudios Jurídicos y Sociales Mispat y Programa de Maestría en Derechos Humanos de la Universidad Autónoma de San Luis Potosí, Aguascalientes/San Luis Potosí, 2014, pp. 163-185.

${ }^{5}$ Bruno Bosteels, "Estado, comuna, comunidad" en Revista Boliviana de Investigación (La Paz) Vol. 11, N 1 (2014), p. 68.

${ }^{7}$ Ernst Bloch, El principio esperanza, Editorial Trotta, Madrid, 2004, p. 27.

8 Pablo Steffanoni, Franklin Ramírez y Maristella Svampa, Las vías de la emancipación: Conversaciones con Álvaro García Linera, Ocean Sur, México, 2009, p. 75.

${ }_{9}^{9}$ Álvaro García Linera, La potencia plebeya, CLACSO/Prometeo, Buenos Aires, 2008, p.38.

${ }^{10}$ Bruno Bosteels, "Estado, comuna, comunidad", Revista Boliviana de Investigación, v. 11, n. 1, agosto 2014.

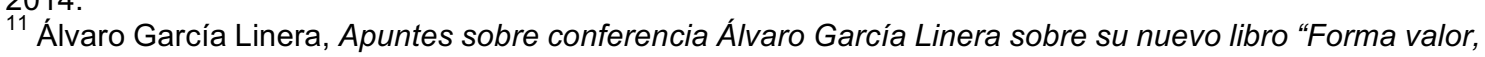
Forma comunidad", La Paz, 2 de septiembre de 2009.

${ }^{12}$ Sobre la concepción del Estado de Carlos Marx, véase por ejemplo a José Rubio Carracedo, Paradigmas de la política, Anthropos, Barcelona, 1990, pp. 113-151.

${ }^{13}$ Enrique Dussel, “¿Estado o comunidad?”, en La Jornada, México, DF, 10 de diciembre de 2009.

${ }^{14} \mathrm{Ver}$, por ejemplo, a Alain Badiou, "Affirmative Dialectics: from Logic to Anthropology" en The International Journal of Badiou Studies (Brooklyn, New York) Vol. 2, N 1.

${ }^{15}$ Véase al respecto a Alain Badiou, ibid.

${ }^{16}$ Karl Marx, "La crítica moralizante y la moral crítica" y "Sobre la cuestión judía”, en Rubén Jaramillo (ed.), Karl Marx. Escritos de juventud sobre el Derecho. Textos 1837-1847, Anthropos, Barcelona, 2008, pp. 164$165,190$.

17 Sobre el particular, véase la interesante obra del catedrático de Harvard Law School, Yochai Benkler, titulada The Penguin and the Leviathan: The Triumph of Cooperation over Self-Interest, Crown Publishing, Random House, New York, 2011.
} 
${ }^{18}$ Se tratan de focos extraestatales de poder popular que, manifestándose autónoma y transversalmente, asumen funciones del Estado en ciertas áreas de interés social tales como la salud, la educación, la producción y distribución de alimentos, entre otros. Se constituyó de facto en una especie de poder dual impulsado desde la Presidencia venezolana para ir dotando al pueblo y a la revolución bolivariana de nuevos instrumentos e instituciones desde las cuales adelantar sus intereses más allá del Estado heredado. Sobre el papel de las misiones y su relación con el proyecto de desarrollo del poder popular en Venezuela, véase por ejemplo a Alfredo Serrano Mancilla, El pensamiento económico de Hugo Chávez, Vadell, Caracas, 2015, pp. 428-463.

${ }^{19}$ Hugo Chávez Frías, Golpe de timón, Caracas, octubre 2012.

${ }^{20}$ Bruno Bosteels, "The Mexican Commune", https://es.scribd.com/doc/247894869/Bosteels-The-MexicanCommune.

${ }_{21}$ Véase, por ejemplo, Salvador Díaz Sánchez, "De la Comuna de París, a la comuna de Cherán", http://www.taringa.net/posts/info/11754160/De-la-Comuna-de-Paris-a-la-comuna-de-Cheran.html.

22 Sobre el particular, véase de Luis Hernández Navarro, "La Comuna de Oaxaca", La Jornada, México, 25 de julio de 2006.

${ }^{23}$ Jaime Martínez Luna, Eso que llaman comunalidad, Culturas Populares, CONACULTA/Secretaría de Cultura, Gobierno de Oaxaca/Fundación Alfredo Harp Helú Oaxaca, AC, Oaxaca, 2010, p. 18.

${ }^{24}$ Erving Goffman, Frame Analysis. Los marcos de la experiencia, CIS, Siglo XXI, Madrid, 2006.

${ }^{*} 25$ Martínez Luna, ibid, p. 56.

${ }^{26}$ Félix Patzi Paco, El sistema comunal: Una propuesta alternativa al sistema liberal, Vicuña, La Paz, 2009, citado en Walter Mignolo, "The Communal and the Decolonial", Turbulence: Ideas for Movement, http://turbulence.org.uk/turbulence-5/decolonial/.

${ }^{27}$ Bolívar Echeverría, "El problema de la nación desde la Crítica de la economía política," El discurso crítico de Marx, Ediciones Era, México, DF, 1986, pp. 179-195.

${ }_{28}^{28}$ Luis Villoro, El poder y el valor. Fundamentos de una ética política, FCE, México, DF, 2012, p. 373.

29 Pablo González Casanova, Los caracoles zapatistas. Redes de resistencia y autonomía (Ensayo de interpretación), México, DF, 11 de septiembre de 2003. 